\title{
Reengineering of the ore preparation production process in the context of "Almalyk MMC" JSC
}

\author{
Margarita Naumova ${ }^{1}$, Ilnur Basyrov ${ }^{1, *}$, and Khakim Aliev ${ }^{1}$ \\ ${ }^{1}$ National University of Science and Technology “MISiS”, Leninskiy prospekt, 4, Moscow, 119049, \\ Russia
}

\begin{abstract}
The review of ore crushing and grinding processes at the mining-and-processing enterprise is presented. An alternative to the standard technology of crushing ore in cone crushers is proposed after a comparative analysis of ore grinding processes.
\end{abstract}

The modern branch of industry is characterized by high costs for the implementation of technological processes based on the disintegration of materials. Mining companies have a complex technological process, one of the stages of which is the process of reducing ore pieces. The extracted mineral in most cases is a mixture of closely intergrown mineral pieces of various sizes. The size of the ore depends on the type of mining and, in particular, on the method of blasting. With open mining, the largest pieces are $1-1.5 \mathrm{~m}$ in diameter, while with underground work they are slightly smaller [1].

To assess the efficiency for the use of technological processes and ore crushing and grinding equipment, when obtaining the final product at JSC "Almalyk MMC", we will perform a comparative analysis of ore preparation.

The process of material pieces or grains reduction by destruction under the influence of external mechanical forces, depending on the size of the final product, is called crushing or grinding (crushing is effected by crushing, splitting, impact forces or a combination thereof, and grinding as a result of impact and abrasive forces). Previously believed that the material destruction during crushing is due to compressive forces, and when grinding from shear. At present, there are no fundamental differences between crushing and grinding, and the difference is only in the size of the starting material and the final product. The types of crushing are distinguished by the size of the obtained product pieces, and the types of crushing are determined by the content of coarse or fine grain classes in the product. It is conditionally considered that during crushing, a product with a maximum grain size of more than $5 \mathrm{~mm}$ is obtained, and when grinding it is less than $5 \mathrm{~mm}$.

Crushing and grinding are preparatory operations of enrichment and are intended for ore grains separation (opening) of various minerals, contained in the mineral in the form of closely intertwined intergrowths. The more fully the minerals are revealed during crushing and grinding, the more successful the subsequent mineral enrichment is.

Evaluation of the crushing and grinding results is performed according to the degree of crushing, grinding and efficiency of crushers and mills.

The degree of crushing or grinding is determined by the formula:

\footnotetext{
*Corresponding author: basirovilnur@mail.ru
} 


$$
i=\frac{A_{\max }}{a_{\max }},
$$

where $A_{\max }$ and $a_{\max }$ - maximum sizes of pieces before and after crushing or grinding.

At the concentrating factories, the ore crushing and grinding is usually carried out in succession in several stages, since it is not possible to obtain the required degree of crushing to fully open the ore mineral in one crushing machine. At each stage, crushers and mills of various types are used, depending on the size of the material [2,3]. The differences in the stage of crushing and grinding depending on the nominal size of the starting material and the final product are shown in Table 1.

Table 1. Limit values of size by stages of crushing and grinding.

\begin{tabular}{|c|c|c|c|}
\hline Stage & $\begin{array}{c}\text { Maximum size of } \\
\text { source material, mm }\end{array}$ & $\begin{array}{c}\text { Maximum size of } \\
\text { crushed (grinded) material, mm }\end{array}$ & $\begin{array}{c}\text { Degree of } \\
\text { crushing } \\
\text { (grinding) }\end{array}$ \\
\hline Crushing: & \multicolumn{3}{|}{} \\
\hline coarse & $1500-500$ & $350-100$ & $4.3-5$ \\
\hline average & $350-100$ & $100-20$ & $3.5-5$ \\
\hline fine & $100-20$ & $20-5$ & $5-4$ \\
\hline Grinding: & $20-5$ & $5-0.1$ & $4-50$ \\
\hline coarse & $5-0.1$ & $0.1-0.05$ and less & \\
\hline fine &
\end{tabular}

The efficiency of crushing is determined by the mass of the crushed material obtained at the expense of a unit of electric power. It, basically, depends on durability of a crushed material. Depending on the size of the resistance during crushing, the ores are classified by hardness: soft (less than $10 \mathrm{MPa}$ ); medium hard (10 - 50 MPa); solid (more than $50 \mathrm{MPa}$ ); very hard (more than $100 \mathrm{MPa})[4,5]$.

When the ore is crushed, the elastic and plastic deformations of the crushed body appear, new surfaces are formed, the forces of internal and external friction are overcome. In connection with the complexity of the process of fragmentation, there is as yet no single universal theory of fragmentation, however, there are two hypotheses - surface and volume.

According to the surface hypothesis, the work spent during crushing is proportional to the value of the newly obtained surface:

$$
E_{\Pi}=K_{\Pi} \cdot S,
$$

where $E_{\Pi}$ - energy consumption for crushing material; $S$ is the area of the newly formed surface; $K_{\Pi}$ - coefficient of proportionality.

Comparing both hypotheses, one can note that the surface hypothesis is more consistent with processes where crushing is carried out by abrasion and partly by cleavage, and the bulk hypothesis to processes in the crushing of bodies by crushing and impact:

$$
E_{0}=K_{0} \cdot V \text {, }
$$

where $E_{0}$ - energy consumption for crushing material; $V$ is the volume of the body; $K_{0}-$ coefficient of proportionality.

Comparing both hypotheses, one can note that the surface hypothesis is more consistent with processes where crushing is carried out by abrasion and partly by cleavage, and the bulk hypothesis to processes in the crushing of bodies by crushing and impact [6].

Consider the scheme of a standard cone crusher (Fig. 1).

The cone crusher is a bowl inside which a conical moving organ is placed. It, in turn, is attached to the shaft, allowing it to move freely inside the bowl. Conical spaces, into which 
the rock particles enter, are formed during the movement between the moving body and the inner surface of the bowl. The ore is poured into the loading hole at the top of the bowl. After the ore enters the tapered space, the moving part starts to move in the opposite direction and creates a high pressure on the ore, which, without sustaining the load, is crushed and falls under the force of gravity into the lower discharge opening. In this case, the surfaces of the movable cone and bowl are covered with a layer of strong steel with a high content of manganese, which significantly extends the life of the components, reducing their wear during operation [7 -9].

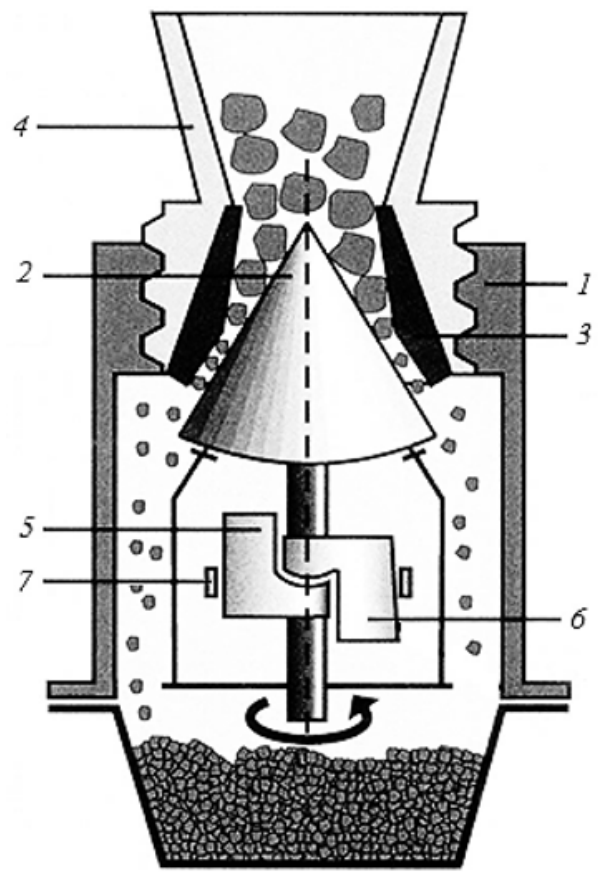

1 - housing; 2 - crushing cone; 3 - outer armor; 4 - funnel; 5 - leading unbalance; 6 -driven unbalance; 7 - amplitude limiter.

Fig. 1. Cone crusher.

Cone crushers are widely used in the processing of various rocks at all stages of crushing $[10,11]$. Depending on the purpose, there are cone crushers for large (CLC), medium (CMC) and fine (CFC) crushing.

Cone crushers are used for crushing not only ore rocks, but also other types of especially hard, abrasive and difficult to crush materials, including materials with a layered, slab-like structure of the piece, as well as for clay ores. They do not need feeders and can work "under the rubble", i.e. with a working space completely filled with ore coming from the above bunker.

Unlike jaw and hammer crushers, cone type devices have a high level of energy consumption. The energy costs go to both phases of the motion of the movable organ. The jaw crushers use a reverse stroke, which significantly reduces electricity consumption, however, the productivity of such devices is lower.

The biggest drawbacks of cone crushers are: more complex and expensive construction, greater height, more complex maintenance, produced noise, and the most important drawback is energy consumption of the machine. Another drawback of the device is the need for periodic replacement of removable steel plates on the working surfaces, which, in 
spite of their high wear resistance, still have a limited service life. Nevertheless, cone crushers have become widespread in a variety of industries.

Let's consider technical characteristics of cone crushers of type $\mathrm{CMC}$ and $\mathrm{CFC}$ (Table 2) [12].

Table 2. Technical characteristics of cone crushers of CMC and CFC types.

\begin{tabular}{|l|c|c|}
\hline \multirow{2}{*}{ Parameter name } & \multicolumn{2}{|c|}{ Standard size of crushers } \\
\cline { 2 - 3 } & CMC 2200Гp & CFC 2200-T1 \\
\hline Efficiency, $\mathrm{m}^{3} / \mathrm{h}$ & $420-700$ & $160-250$ \\
\hline Aperture, $\mathrm{mm}$ & 350 & 100 \\
\hline Nominal width of discharge hole, $\mathrm{mm}$ & $30-60$ & $5-15$ \\
\hline The biggest size of materials in feeding, $\mathrm{mm}$ & 300 & 85 \\
\hline Power of electric engine, $\mathrm{kW}$ & 250 & 250 \\
\hline Power supply voltage, $\mathrm{W}$ & 6000 & 6000 \\
\hline Lag frequency of the crushing case, $\mathrm{r} / \mathrm{min}^{-1}$ & 242 & 242 \\
\hline Crusher's mass, $\mathrm{t}$ & 92 & 93 \\
\hline Size of the finished product, $\mathrm{mm}$ & 75 & 21 \\
\hline
\end{tabular}

As an alternative to the standard technology (three-stage crushing in crushers with subsequent grinding in rod and ball mills), we will consider the semi-self-grinding (SSG) process. For a long time, its high sensitivity to the variability of the physical and mechanical properties of the processed raw materials and the higher energy intensity compared to standard technology hindered the wide introduction of this process. It was believed that the best selfgrinding results were achieved when processing wet, sticky and clay raw materials, when crushing in cone crushers was ineffective or there were difficulties in transporting and storing crushed products. After successful approbation of such ways of self-grinding process intensification as loading of steel balls into the mill, withdrawal of hard-to-break critical size grades from the mill, their subsequent refinement in a separate cycle, the area of their application has significantly expanded. With the development of intensified methods, the productivity of SSG mills (SSGM) increased, and they started to be used to grind stronger ores. The technology of self-grinding for various types of mineral raw materials became virtually universal and in most cases it provides high technical and economic indicators $[13,14]$.

The advantage of the SSG process is the ability of SSGM to work on coarse-grained ore. In this case, for a long time large feeding was considered favorable both for selfgrinding and SSG. At the same time, experience of many years of the majority of enterprises shows that for an effective operation of SSGM not only the size of the maximum piece is required, but a certain ratio in the feeding of mills of fine fractions, coarse fractions and intermediate size material.

Wet semi-self-grinding mills of WSGM type (Fig. 2) are used, mainly, in the first stage of grinding in a two-stage mode. The use of large mills allows to exclude the stages of medium and fine crushing, and in some cases of large crushing [15].

Self-grinding mills (SGMs) and SSGMs are usually used to grind initial ore or the first stage crusher product. The size of the mill feeding is limited only by the size of the pieces that can be actually transported and loaded into the mill. The mill product may be of a size already suitable for processing, or be of intermediate size suitable for final grinding in a ball mill, pebble mill or a vertical mill.

Self-grinding/semi-self-grinding mills can perform grinding work equal to the operation of two or three stages of crushing and sorting of a core mill, and in whole and in part the operation of a ball mill. Due to the wide choice of mill sizes, self-grinding/semi-self-grinding can be performed with fewer lines than in a conventional scheme: core mill - ball mill. 
All of the above gives savings in capital expenditures and lower maintenance costs of the SGM/SSGM scheme and explains the popularity of this type of grinding in modern mining and processing enterprises. In some ore bodies due to the moisture and clay contained, crushing and sorting are considered difficult, if not impracticable. Reducing the number of redistributions using the SGM/SSGM seems most preferable.

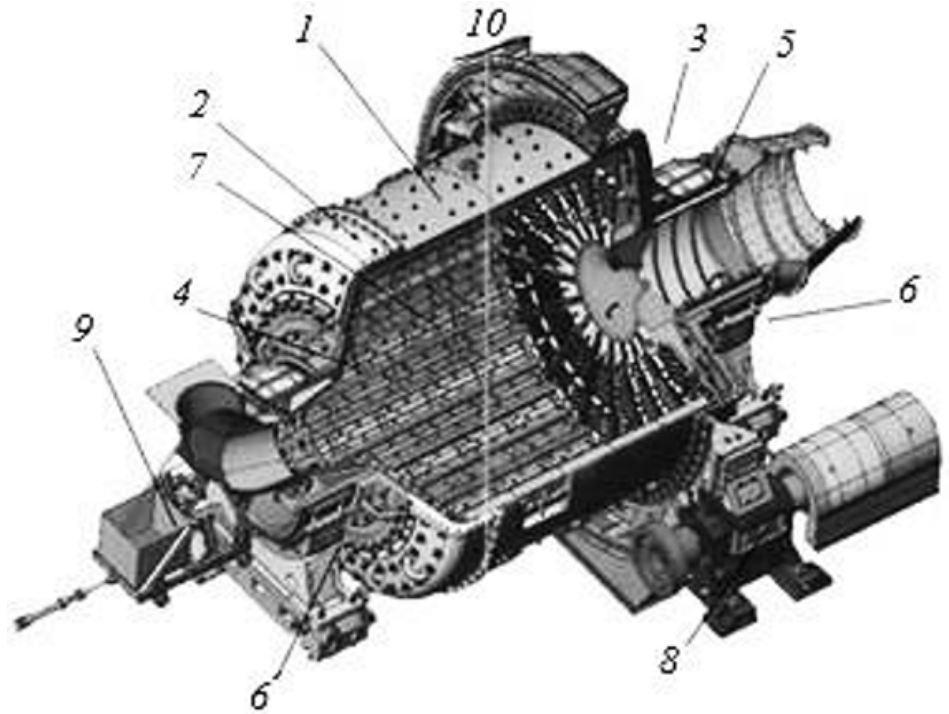

1 - cylindrical drum; 2,3 - end caps; 4 - unloading pin; 5 - charging pin; 6 - radical bearings; 7 - lining plates; 8 - low-speed drive; 9 - feeding chute; 10 - crown gear.

Fig. 2. Wet semi-self-grinding mill (WSGM).

Technical characteristics of the wet semi-grinding mill of WSGM-9500x5400 type are given in Table 3 [16].

Table 3. Technical characteristics of WSGM.

\begin{tabular}{|c|c|}
\hline Parameter name & WSGM-9500x5400 \\
\hline Mill capacity by source ore, $\mathrm{t} / \mathrm{h}$ & $650-1105$ \\
\hline Internal drum dimensions, $\mathrm{mm}($ diameter $\times$ length $)$ & $9500 \times 5400$ \\
\hline Nominal drum volume, $\mathrm{m}^{3}$ & 337.5 \\
\hline Nominal rotation speed of the mill drum, min $^{-1}$ & 11 \\
\hline Degree of drum pulp filling, not more than $\%$ & 45 \\
\hline \multicolumn{2}{|l|}{ Main drive motor DSRAJ 8037-8WF } \\
\hline Nominal power on the motor shaft, $\mathrm{kW}$ & 5000 \\
\hline Network voltage, $\mathrm{V}$ & 6000 \\
\hline Rotational speed, min $^{-1}$ & 750 (simult.) \\
\hline $\begin{array}{l}\text { Note - Capacity of the mill depends on } t \\
\text { material to be crushed, the accepted process schen } \\
\text { determined in each individual case at the site of ope }\end{array}$ & $\begin{array}{l}\text { mical properties of the } \\
\text { hd other factors and is }\end{array}$ \\
\hline
\end{tabular}

WSGM type mill is designed for wet semi-self-grinding of ore. The mill is operated with continuous feeding of ore and water into the cavity of the rotating drum. To increase productivity, balls are added to the mill to fill $10 \%$ of the drum volume. Balls are fed automatically through a ball-shaped device $[17,18]$. The ore, together with the balls, is gripped by ribs of special constructions and rises upwards until the radial component of gravity exceeds the centrifugal force, after which the pieces of ore and balls fall down and, hitting against the lining and against each other, split. In this case, there is a constant 
mixing of ore and balls, during which the ore is crushed by splitting, crushing and abrasion. The crushed material, the size of which becomes smaller than the size of the discharge grid, together with the water (pulp) passes through the cracks and is discharged through the intermediate sleeve.

For automatic continuous extraction of metal scrap at the outlet of the pulp from the wet semi-self-grinding mill, a magnetic scrap-removal system is installed directly on the output flange of the ball mill [19-21].

Compared with grinding in ball and core mills, self-grinding has several advantages: - capital costs and operating costs for crushing and grinding operations are drastically reduced; - the ore grinding conditions are improved, since the opening of useful minerals occurs predominantly between the grains along the weakest cleavage planes;

- favorable grinding conditions allow to increase technological enrichment indicators;

- labor productivity significantly increases.

The comparative analysis of ore preparation at "Almalyk MMC" JSC showed that the application of the ore grinding process in wet semi-self-grinding mills, as an alternative to the standard ore crushing technology in cone crushers with subsequent grinding, is more effective in obtaining the final product at the enterprise. Due to the wide choice of the sizes of the SGM/SSGM, self-grinding/semi-self-grinding can be performed with fewer lines than the usual crushing and grinding scheme.

\section{References}

1. V.R. Revnivcev, Selective destruction of materials (Moscow, Nedra, 1988)

2. S.M. Gorbatyuk, V.M. Pavlov, A.N. Shapoval, M.S. Gorbatyuk, Metallurgist 42 (5-6), pp. 178-183 (1998)

3. N.V. Pasechnik, A.Yu. Zarapin, N.A. Chichenev, Shuiyun Gongcheng/Port \& Waterway Engineering 11, pp. 58-64 (1998)

4. A.Yu. Zarapin, I.A. Levitskij, A.S. Mokretsov, N.A. Chichenev, Stal' 7, pp. 61-64 (1999)

5. A.N. Shapoval, A.A. Shapoval, Tsvetnye Metally 4, pp. 77-82 (2002)

6. E.V. Bratkovskij, A.V. Zavodyanyj, A.E. Parenkov, Laboratory course "Extraction of ferrous metals from natural and technogenic raw materials" (Orck, "Market servis", 2008)

7. A.Yu. Zarapin, S.E. Stanishevskij, A.N. Chichenev, Tyazheloe Mashinostroenie 6, pp. 21-25 (1999)

8. S.P. Eron'ko, M.Y. Tkachev, E.V. Oshovskaya, Russian Metallurgy (Metally) 6, pp. 441-446 (2017)

9. A.L. Sotnikov, A.A. Sholomitskii, Metallurgist 60 (9-10), pp. 1046-1053 (2017)

10. N.L. Kirillova, A.G. Radyuk, A.E. Titlyanov, Metallurgist 57 (9-10), pp. 878-882 (2014)

11. N.L. Kirillova, A.G. Radyuk, A.E. Titlyanov, S.M. Gorbatyuk, Steel in Translation 43 (5), pp. 231-235 (2013)

12. http://www.tyazhmash.com/products/construction/mill-sag/

13. S. Bratan, P. Novikov, S. Roshchupkin, Procedia Engineering 150, pp. 802-808 (2016)

14. A.Yu. Zarapin, A.N. Chichenev, Tyazheloe Mashinostroenie 6, pp. 16-20 (1999)

15. http://промкаталог.pф/PublicDocuments/1303901.pdf

16. http://rivs2010.rivs.ru/wp-content/uploads/2010/12/5skarin.pdf

17. A.D. Zobnin, M.G. Naumova, Stal' 9, pp. 63-64 (2014) 
18. A.D. Zobnin, M.G. Naumova, I.G. Morozova, SevNTU Bulletin 150. Mechanical Engineering and Transport (2014)

19. S.M. Gorbatyuk, I.G. Morozova, M.G. Naumova, Izvestiya Vysshikh Uchebnykh Zavedenij. Chernaya Metallurgiya 60 (5), pp. 410-415 (2017)

20. S.M. Gorbatyuk, I.G. Morozova, M.G. Naumova, Steel in Translation 47 (5), pp. 308-312 (2017)

21. V. Kukhar, V. Artiukh, O. Serduik, E. Balalayeva, Procedia Engineering 165, pp. 1693-1704 (2016) 